\title{
INVESTIGATION OF ALLERGEN PROTEINS IN FIVE TOMATO CULTIVARS
}

\author{
R.T. Mócsai ${ }^{\mathrm{ab} *}$, A. Maczóa ${ }^{\mathrm{a}}$, C. Grünwald-Gruber ${ }^{\mathrm{b}}, \mathrm{K}$ Majer-Baranyi ${ }^{\mathrm{a}}$, N. AdÁnyi ${ }^{\mathrm{a}}$, \\ P. Milotay ${ }^{\mathrm{c}}, \mathrm{J}_{\text {. Czelecz }}^{\mathrm{d}}$ and R. TÖMÖSKÖZI-FARKAS ${ }^{\mathrm{a}}$ \\ ${ }^{a}$ Food Science Research Institute, National Agricultural Research and Innovation Centre, \\ H-1022 Budapest, Herman Ottó út 15. Hungary \\ ${ }^{\mathrm{b}}$ Department of Chemistry, University of Natural Resources and Life Sciences, \\ Muthgasse 18. 1190 Vienna. Austria \\ ${ }^{c}$ Vegetable Crop Research Department, National Agricultural Research and Innovation Centre, \\ H-6000 Kecskemét, Mészöly Gyula út 6. Hungary \\ ${ }^{\text {d} B e t h e s d a ~ C h i l d r e n ' s ~ H o s p i t a l, ~ H-1146 ~ B u d a p e s t, ~ B e t h e s d a ~ u . ~ 3 . ~ H u n g a r y ~}$
}

(Received: 20 October 2016; accepted: 18 January 2017)

\begin{abstract}
Investigation of putative allergens from tomato berries is challenging as differences between human serum IgE specificity and reactivity as well as the non-specific binding of the primary and secondary antibodies often cause difficulties. In this study five tomato cultivars were investigated to evaluate their potential allergenicity in Hungarian tomato sensitive patients. The major allergens proved to be low molecular weight proteins, but several previously described allergens could be identified as well using IgE-Western blotting. IgE binding to cross-reactive carbohydrate determinants (CCDs) was ruled out through the use of CCD inhibitor, but non-specific binding of the secondary antibody remained an issue. IgE binding activity of a purified, immunoblot positive protein (band at $40 \mathrm{kDa}$ ), and non-specific binding of the secondary antibody to the same protein, was demonstrated with an Optical Waveguide Lightmode Spectroscopy (OWLS) based immunosensor. LC-ESI-MS/MS analysis showed this protein is an as-yet undescribed vicilin-type putative allergen.
\end{abstract}

Keywords: tomato allergens, immunosensor, IgE non-specific binding, LC-ESI-MS/MS

Tomato belongs to the nightshade family, several members of which were previously reported as allergenic. The prevalence of tomato allergy ranges from $1.7 \%$ to $9.3 \%$ in different populations of Europe with an average of $4.9 \%$ (BURNEY et al., 2014). It is mainly affecting southern regions of Europe, therefore most of the studies were concentrating on Italian and Spanish (BEnCivenni et al., 2012; López-Matas et al., 2014) populations, but there are also a number of publications from Germany (WESTPHAL et al., 2003). The most frequent symptoms of tomato allergy are local symptoms, mainly oral allergy syndrome, characterized by $\operatorname{IgE}$ mediated reactions, or cutaneous symptoms such as erythema, pruritus or hives after contact or ingestion. Systemic reactions are not very common (AsERo et al., 2009). However, in some cases tomato seems to be inducing food-dependent exercise induced anaphylaxis (Romano et al., 2012). Tomato allergy was proved to be linked to other allergies by cross-reactivity (MARTINo et al., 1988). Patients with tomato allergy have been generally advocated strict avoidance of tomato. As food allergy is increasing worldwide, new and more practical methods should be developed for allergen investigation (ASERO, 2013).

\footnotetext{
* To whom correspondence should be addressed.

Phone: +36 1 796-0400; fax: +36 1 796-0449; e-mail: rekamocsai@groupwise.boku.ac.at
} 
So far, seven tomato allergens are listed at the International Union of Immunological Society's (I.U.I.S.) database. Lyc e 1 (profilin), Lyc e 2 ( $\beta$-fructofuranosidase), Lyc e 3 (nonspecific lipid-transfer proteins), Lyc e 4 (intracellular pathogenesis-related protein), Lyc e 5 (cyclophilin), Lyc e 6 (7 kDa lipid transfer protein), and Lyc e 7 (11 kDa lipid transfer protein) are the confirmed allergens. However, many other IgE binding proteins have been reported in the literature. Some of these putative allergens are already available at the Allergome database, but there is only preliminary data available on their allergenicity. Some of these proteins have glycosylation sites that can induce the production of anti-glycan IgE antibodies. Although the clinical significance of these carbohydrate-binding antibodies has not yet been ruled out, most of the field's researchers suggest that these CCD specific IgEs are not relevant from a clinical point of view, since they do not induce symptoms (Ево et al., 2004; MARI et al., 2008). These CCDs play a role in misinterpreting the allergenicity of proteins due to false positives. CCDs occur mostly on allergens from plants and insects, but with competing glycopeptides CCD specific IgEs can be inhibited (HoLzweBER et al., 2013). However, even if this challenge is solved, there is still a diagnostic problem, since the secondary antibodies sometimes also give false positive results through non-specific binding to plant proteins (LASNE, 2001). In our study, one selected putative seed allergen (vicilin) was further examined to collect more data on its IgE binding capacity, and its non-specific binding to horseradish peroxidase (HRP) conjugated secondary antibody. Since its discovery in 2009 by BäsSLER and co-workers, no additional data was published of this seed storage protein, even though its homology to major nut allergens indicates its clinical importance.

Using sera from Hungarian tomato sensitive patients, five tomato cultivars were screened by a proteomic approach, in order to identify the major allergens and evaluate the differences in IgE binding properties of these cultivars. Furthermore, two vicilin fragments were purified then identified by LC-ESI-MS/MS, and their immunoglobulin binding capacity was further investigated by OWLS based immunosensor. Biosensors might be an alternative method to the conventional immunoanalytical procedures. The systems based on immunoreaction generally rely on highly selective and sensitive devices to translate the biological recognition process (antibody-antigen binding) into a physical magnitude variation in real time.

\section{Materials and methods}

\subsection{Tomato cultivars}

Tomato samples were provided by the Vegetable Crop Research Department, NARIC. Five tomato cultivars were selected from open field cultivation in 2015. Aragon and Solerosso are processing types; Noemy, Korall and cherry-type Cherrola are fresh market commercial cultivars. All samples were cultivated in Kecskemét, Hungary with the same conditions, and were at similar ripening stage at harvest.

\subsection{Preparation of tomato extracts}

Fruits were peeled ( $2 \mathrm{~mm} \pm 0.2 \mathrm{~mm}$ ) and granum, exocarp, and mesocarp tissues were freezedried separately. Dried samples were ground with avoidance of excessive heat. Protein extraction was carried out from powder with phosphate saline buffer solution $(\mathrm{pH} 7.4 ; 1.5 \mathrm{~h}$; $4{ }^{\circ} \mathrm{C}$ ) with gentle agitation. The total protein content was measured from supernatant in triplicates with a Qubit fluorometer (Invitrogen), according to the manufacturer's instructions. 


\subsection{Gel electrophoresis and Western blotting}

Proteins were separated on 14\% SDS-polyacrylamide gel (Mini Protean kit, Bio Rad). Gels have been stained with Coomassie Blue and detection of glycoproteins was done by Schiff staining (ZACHARIUS et al., 1969). Western blotting was carried out by the classical way on a polyvinylidene fluoride membrane (pore size $0.45 \mu \mathrm{m}$ ) using anonym human tomato sensitive sera. The five tomato sensitive serum samples and the negative control serum sample used in this study were obtained from the Bethesda Hospital (Budapest, Hungary) with approval of the local ethic committee. As secondary antibodies, alkaline phosphatase (AKP) conjugated mouse anti-human IgE (BD Pharmingen) and HRP conjugated goat anti-human IgE (Sigma Aldrich) were used. To achieve gentle inhibition of anti-CCD IgE, competing glycoconjugates were used in excess. The CCD-blocker used for this purpose is a half-synthetic glycopeptide (ProGlycAn).

\subsection{Purification of selected protein band}

The $40 \mathrm{kDa}$ fraction was purified from the granum extract by ion exchange fast protein liquid chromatography (IE-FPLC) using a self-packed Q Sepharose fast flow anion exchange column and Äkta UPC10 instrument (GE Healthcare). A $50 \mathrm{mmol} \mathrm{l}^{-1}$ Tris-HCl buffer (pH 8.4) was used at a flow rate of $1 \mathrm{ml} \mathrm{min}^{-1}$. A linear gradient up to $0.5 \mathrm{~mol} \mathrm{l}^{-1} \mathrm{NaCl}$ was applied over $60 \mathrm{~min}$. The collected fractions were checked by SDS-PAGE.

\subsection{In-gel digestion of protein bands}

The gel bands of the fractions were excised and destained with 50\% acetonitrile (ACN) in 25 mmol 1-1 $\mathrm{NH}_{4} \mathrm{HCO}_{3}$. Proteins were reduced (addition of $10 \mathrm{mmol} \mathrm{l}^{-1}$ dithiothreitol; $45 \mathrm{~min} ; 56$ ${ }^{\circ} \mathrm{C}$ ) and carbamidomethylated (addition of $55 \mathrm{mmol} \mathrm{l}^{-1}$ iodoacetamide; $30 \mathrm{~min} ; 22{ }^{\circ} \mathrm{C}$ ) in gel. The proteins were digested with trypsin (modified Trypsin, Promega) over night at $37{ }^{\circ} \mathrm{C}$. Obtained tryptic peptides were washed out of the gel and dried in a speed-vac concentrator (Savant). The samples were reconstituted in HQ-water before injection.

\subsection{LC-ESI-MS/MS measurement}

The peptide mixtures were analysed with a Dionex Ultimate 3000 LC-system (using a RP capillary column, $150 \times 0.32 \mathrm{~mm}$ BioBasic- 18 , Thermo Scientific) directly coupled to a Bruker maXis 4G Q-TOF MS instrument with the standard ESI source. Spectra were recorded in positive ion data depended acquisition mode. Proteins were identified using MASCOT (Matrix Science) by MS/MS ion search. A score higher than 30 was necessary for a positive hit.

\subsection{Immunosensing}

Immunosensing was carried out with an OWLS 210 Model (MicroVacuum Ltd., Hungary) and integrated sensors type of OW2400 from the same manufacturer. Silanization of chips and immobilisation was carried out by the method of ADÁNYI and co-workers (2006). The immobilisation of purified antigen $\left(2 \mu \mathrm{g} \mathrm{ml}^{-1}\right)$ was performed immediately before the measurements in flow through system. After baseline stabilization, the surface was washed with $50 \mathrm{mmol}^{-1} \mathrm{HCl}$. Further steps were performed in the presence of $42 \mathrm{mmol} \mathrm{l}^{-1}$ Tris buffer

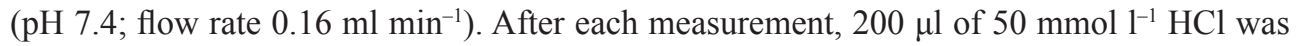
applied to dissociate the antigen-antibody complexes, thus regenerating the sensor. To detect 
binding of the secondary antibody, anti-bovine serum albumin (aBSA) (Sigma Aldrich) was used as negative control. As for the serum measurements, soy allergic human serum was applied as negative control.

\section{Results and discussion}

\subsection{Classical proteomic analysis}

Total protein contents of the extracts from granum tissues were significantly higher $\left(1347.5 \pm 210 \mu \mathrm{g} \mathrm{ml}^{-1}\right)$ in every cultivar than from exocarp tissue $\left(796.5 \pm 21.32 \mu \mathrm{g} \mathrm{ml}^{-1}\right)$ and mesocarp tissue $\left(441 \pm 30 \mu \mathrm{g} \mathrm{ml}^{-1}\right)$. SDS-PAGE patterns revealed protein bands between 6 and $70 \mathrm{kDa}$ molecular weight with visually corresponding quantity to the measured protein contents (Fig. 1A). Low level of variability was observed in the protein patterns of tomato genotypes. After Schiff staining, several glycoproteins were detected in the molecular weight region at $26-70 \mathrm{kDa}$, mainly in exocarp and mesocarp extracts (data not shown). In agreement with BENCIVENNI and co-workers (2012), pooled serum samples from five tomato sensitive patients were used for IgE-Western blotting in order to evidence the most important allergens and to estimate general allergenicity. Many Schiff-positive high molecular weight protein bands showed immunoactivity, mainly of exocarp and mesocarp origins, indicating the involvement of glycan structures (Fig. 1B). In order to assess whether the IgE reactivity is really due to the presence of CCDs or it is peptide specific, CCD inhibition (Fig. 1C) was carried out.

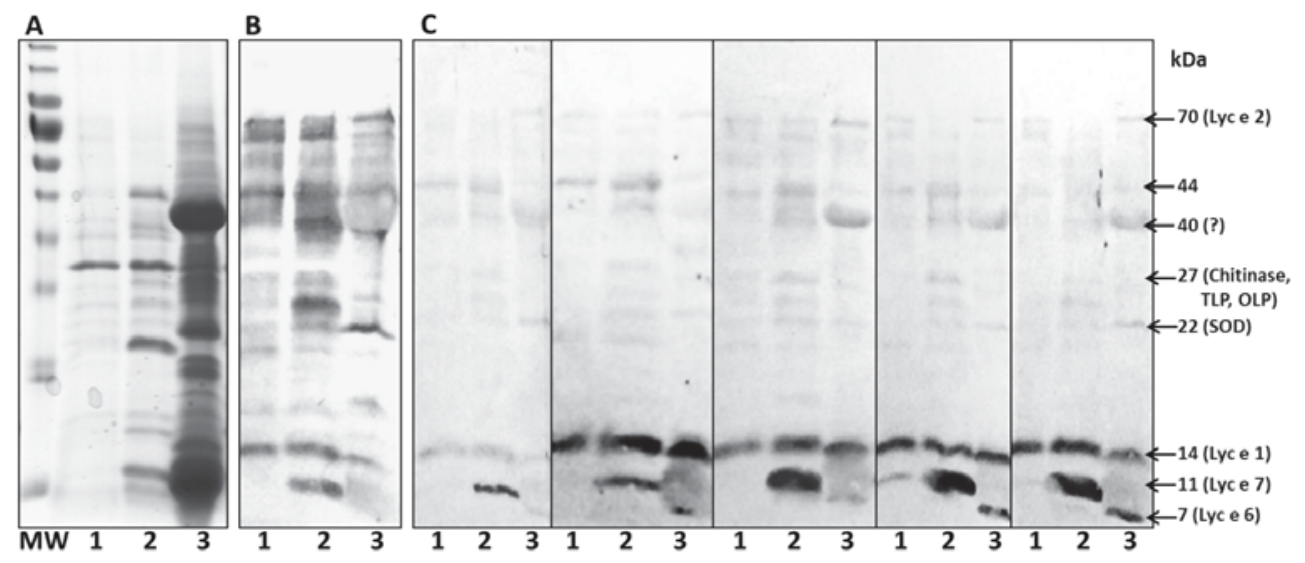

Fig. 1. Results of Coomassie stained SDS-PAGE (A), classical immunoblotting (B) and immunoblotting with CCD inhibition with protein extracts from the five different cultivars $(C)$. Cultivars from left to right: Cherrola, Korall, Solerosso, Noemy, Aragon. Allergens in the same molecular weight region are presented next to the molecular weight indicators. Legends: MW: molecular weight markers (Thermo Scientific PageRuler); 1: mesocarp tissue extract; 2: exocarp tissue extract; 3: granum tissue extract

After CCD inhibition, several bands remained in the molecular weight region of wellknown allergens. The most intensive bands were detected in the 7, 11, and $14 \mathrm{kDa}$ region, which correspond to $L y c$ e 6, Lyc e 7, and Lyc e 1, respectively. Based on these results we suspect, that these proteins are the major IgE binding allergens for Hungarian population, 
although for general conclusions more data with the involvement of greater number of patients is needed. Findings of BENCIVENNI and co-workers (2012) confirm this assumption, as they also found Lyc $e 1$ to be the most abundant allergen reacting with Italian patients' sera. Interestingly, the low molecular weight proteins of Cherrola seem to react weaker than of other cultivars. In the higher molecular weight region, the $70 \mathrm{kDa}$ band was present in all cultivars mainly in the seed extracts, and corresponds to Lyc e 2 according to the MW data. The $40 \mathrm{kDa}$ band was only detectable in seed extracts, and was very intensive in Solerosso cultivar. Non-specific binding of the HRP conjugated secondary antibody was only observed at the $40 \mathrm{kDa}$ and the $26 \mathrm{kDa}$ molecular weight region of the granum extract, while the AKP conjugated antibody reacted to the $11 \mathrm{kDa}$ exocarp protein in buffer controls (Fig. 2).

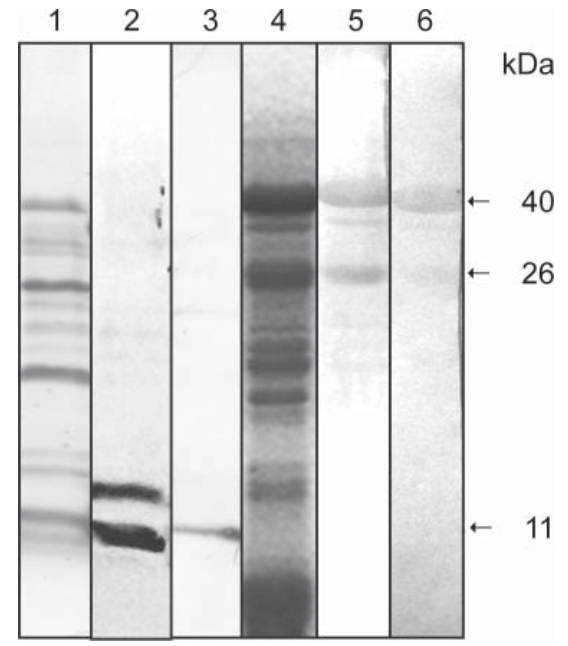

Fig. 2. Non-specific binding of two different secondary antibodies in the immunoblots obtained without using primary antibody. Legends: 1: Coomassie stained gel of exocarp tissue extract; 2: immunoblot with pooled tomato sensitive sera and AKP conjugated secondary antibody; 3: immunoblot buffer control with AKP conjugated secondary antibody; 4: Coomassie stained gel of granum tissue extract 5: immunoblot with pooled tomato sensitive sera and HRP conjugated secondary antibody; 6: immunoblot buffer control with HRP conjugated secondary antibody

This could forecast doubts in the allergenic activity of these seed proteins, so further purification steps and analyses were conducted. The IE-FPLC fractionated protein peak consisted of both the $40 \mathrm{kDa}$ band and the $26 \mathrm{kDa}$ band that afterwards still showed immunoactivity in IgE-Western blotting, so they were both selected for further analysis.

\subsection{Mass spectrometry}

The MASCOT search against database restricted to tomato showed one positive hit, vicilin (Uniprot accession: B0JEU3 SOLLC; Mascot score 2278.9 with the total of 44 identified peptides) with the molecular mass of $66.178 \mathrm{kDa}$ referring to the dimerization of this two bands. No other protein's hit reached the Mascot score limit of 30 . The sequence coverage of both fragments is shown in Figure 3. 
A

\begin{tabular}{|c|c|c|c|c|}
\hline MAT PUK PKTII & FIFBLILSLV & IVSQCYDQNP & REYQDEQBKI & RECQQRCBRQ \\
\hline QREQQK QICK & QRCEQQYRKE & QQQHEGETE & BDDHENRGPD & KS YKRL $Q E C Q$ \\
\hline RRCQSEQQGQ & RLQECQQRCQ & QZYQRBKEQH & QGMNPQWIEQ & QBKSNNPYLF \\
\hline ESQR FRSRRR & ASHGDFR & RENQRSQLLK & GIJKYRVAIL & ELEPQSEVLP \\
\hline HHCDGEAIYV & VVRGQGVINI & AEQDNKNSFN & $L_{Q} K G D V I R L F$ & AGSNVYLLNK \\
\hline DNNERL FVYV & LAR.SVNAPGN & IQEY FSAGGQ & NPESFYRAFS & SDILESAFNN \\
\hline PRDKLERLFG & QHKEGIIIKA & SEEQIRAISE & HASRSIQQIR & GR TQGP FNLM \\
\hline KERPVFESRF & GQFFEARPER & YEQL RDLDAA & VGRMNINQGG & MV L PYYNTKS \\
\hline IK L LVMV IEGN & ARFEMACPHL & GRQS QSPWSR & $G Q G R E Q E R E Q$ & EQEQEEGDVH \\
\hline$Y Q R$ IR GNLNV & GDVLVIPAGH & PITFVATGNS & NLRIVGFGVD & AENNKRNFLA \\
\hline GRQNIWRNID & REAKELSESM & PGREVEEIFQ & RQDQSYFVAG & PEHRQQRSRE \\
\hline BEGRRE $Q D Q Y$ & ISSIIDFVE & & & \\
\hline
\end{tabular}

B

\begin{tabular}{|c|c|c|c|c|}
\hline WA TFNK PKLI & FIFFIILSUV & IVSQCYDQNP & RGYQDP QझKL & RECQQRCBRQ \\
\hline QPEQQK QICK & QRCEQQYRKE & QQQHGEBTG & BDDIGNRGPD & KSYRRIQECQ \\
\hline RRCQSEQQRG & RIQECQQRCQ & QEYQRBKGQH & QGEINP QWEQ & QBKSNNPYLE \\
\hline ESQRERSRFR & ASHEDFRILE & RENQRSQILK & GIBKYRVAIL & ELEPQSEVLP \\
\hline HHCDGEAIYV & VVKGQGVINI & AEQDNRNSFN & LQRGDV IRLF & AGSNVYLLNK \\
\hline DNNBK L FVYV & LAKSVNAPGN & LQEY FSAGGQ & NPESFYRAFS & SDILESAFNN \\
\hline PRDKLERLFG & QHKEGIIIKA & SEEQIRAISE & HASRSIQQIIR & GRTQGPFNLM \\
\hline KERPVFESRF & GQFFEARPER & YEQL RDLDAA & VGFMNI NQGG & MV LPYYNTK 5 \\
\hline DK LVMV IEGN & ARFEMACPHL & GRQS QSPWSR & GQGRBQBREQ & EQEQEEGDVH \\
\hline YQR IRGNLNV & GDVLVIPAGH & PITFVATGNS & NLRIVGFGVD & AENNR WNFIA \\
\hline GKQNINRNID & REAKMLSESM & PGREVEBIFQ & RQDQSY FVAG & PEHRQQRBRG \\
\hline BSERREQDQY & ISSIIDFVE & & & \\
\hline
\end{tabular}

Fig. 3. Sequence coverage of the tomato vicilin A: $40 \mathrm{kDa}$ and B: $26 \mathrm{kDa}$ fragments. Black letters: Identified peptides, White letters: data not recovered

Concluding from the sequence homology, these seed storage proteins can represent allergenic potential, since major seed allergens from walnut, sesame, hazelnut, and peanut are also $7 \mathrm{~S}$ vicilins. As these proteins are proved allergens and already registered in the I.U.I.S database, sequence identities (30-47\%) and conformational similarities (66-81\%) (BäsSLER et al., 2009) suggested that tomato vicilin might contain similar putative epitopes.

\subsection{Immunosensing}

The isolated vicilin fraction of granum protein was immobilised on the chip. Comparing the binding of the HRP conjugated secondary antibody with aBSA serving as negative control, the anti-human $\mathrm{IgE}$ provided higher initial reaction rates, meaning stronger binding capacity (Fig. 4). These results were in agreement with the attained immunoblotting results, further proving that non-specific binding of the secondary antibody occurs. 


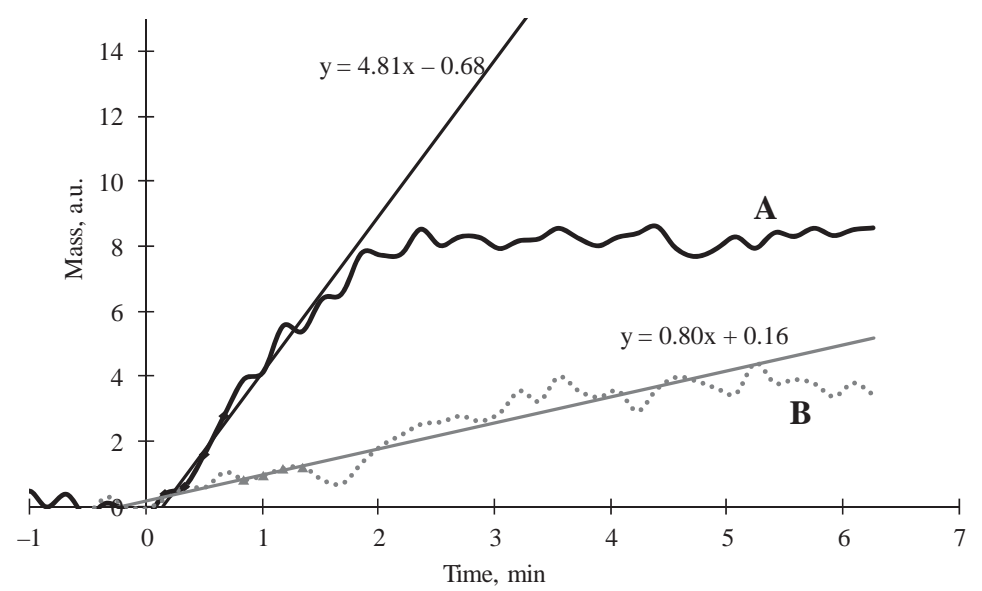

Fig. 4. Results of OWLS based immunosensing using the HRP conjugated secondary antibody. The anti-human $\operatorname{IgE}(\mathrm{A})$ used as secondary antibody for different immunoanalytical methods bound to the immobilised tomato vicilin fragment, as higher initial reaction time shows. Anti-BSA (B) was used as control, and the typical diagram showed no significant binding capacity

To gather information on the human IgE binding capacity, tomato sensitive sera from four different patients were loaded onto the sensor. Immunosensing has the advantage of investigating antigen-antibody binding without the need of secondary antibodies. Individual measurements showed binding capability to the immobilized tomato vicilin in all four cases (Fig. 5). This result suggests that the vicilin fragment contains IgE binding epitopes. Difference between the initial reaction rates of tomato sensitive sera compared to the negative control was smaller than expected, which could be explained by cross-reactivity as the negative serum sample was obtained from a soy sensitive patient.

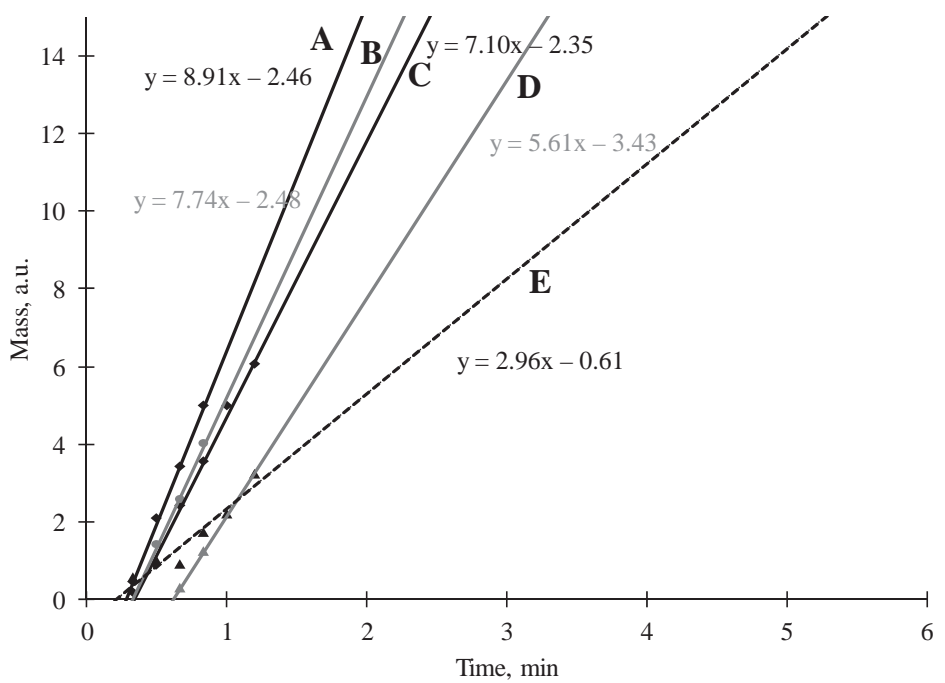

Fig. 5. Results of OWLS based immunosensing using tomato sensitive human sera. Legends: A, B, C, D: tomato positive sera from different patients; E: soy positive serum served as negative control. The IE-FPLC purified vicilin fragment was immobilised on the sensor 


\section{Conclusions}

The immunology based methods used for allergen identification have critical points regarding the nature of the antigen and the detection methods. For the nature of the antigen, this critical point is the presence of CCDs on the protein chain. For the detection methods, the nonspecific binding of the secondary antibody may cause false results. Here we tried to find new aspects to get closer to the solution of these challenges in the identification of tomato allergens. The IgE binding to carbohydrate determinants was successfully ruled out by CCD inhibition. The non-specific binding of the secondary antibodies to the antigen were investigated using AKP and HRP conjugated antibodies. The HRP conjugated secondary antibody showed non-specific binding to a vicilin-type tomato allergen, which was identified by LC-ESI-MS/MS. The non-specific binding was further proved by OWLS based immunosensing, but the cause of the binding remains unknown. Though investigated vicilin showed binding properties to tomato sensitive human sera, no proof is obtained to nominate this protein as allergen, and further investigations with sensitivised patients` sera are needed. Several well-described tomato allergens were detectable through immunoblotting after CCD inhibition, and the most clearly visualized bands were Lyc e 1, Lyc e 7, and Lyc e 6. Several other bands showed immunoactivity, and the goal to discriminate between cultivars was achieved.

The financial support of the Hungarian Ministry of Agriculture is highly appreciated. Authors thank the research group of Friedrich Altmann (BOKU, Austria) for providing the CCD blocker and assistance in MS measurements. MicroVacuum Ltd. supported this work by providing measurement time on the OWLS 210 instrument and by supplying sensor chips. Authors are also grateful for the Bethesda Hospital in Hungary for providing patients' sera.

\section{References}

AdÁNYi, N., VÁradi, M., Kim, N. \& Szendrö, I. (2006): Development of new immunosensors for determination of contaminants in food. Curr. Appl. Phys., 6(2), 279-286.

AsERo, R. (2013): Tomato allergy: clinical features and usefulness of current routinely available diagnostic methods. J. Invest. Allerg. Clin., 23(1), 37-42.

Asero, R., Antonicelli, L., Arena, A., ... \& S Senna, G.E. (2009): Causes of food-induced anaphylaxis in Italian adults: a multi-centre study. Int. Arch. Allerg. Imm., 150(3), 271-277.

Bässler, O.Y., Weiss, J., Wienkoop, S., Lehmann, K., Scheler, C., Dölle, S., Schwarz, D., Franken, P., George, E., Worm, M. \& Weckwerth, W. (2009): Evidence for novel tomato seed allergens: IgE-reactive legumin and vicilin proteins identified by multidimensional protein fractionation - mass spectrometry and in silico epitope modeling. J. Proteome Res., 8, 1111-1122.

Bencivenni, M., Faccini, A., Bottesini, C., Rao, R., Detoraki, A., Ridolo, E., Marone, G., Dall'Aglio, P.P., Dossena, A., Marchelli, R. \& Sforza, S. (2012): Assessing allergenicity of different tomato ecotypes by using pooled sera of allergic subjects: identification of the main allergens. Eur. Food Res. Technol., 234, 405-414.

Burney, P.G.J., Potts, J., Kummeling, I., Mills, E.N.C., ... \& van Ree, R. (2014): The prevalence and distribution of food sensitization in European adults. Allergy, 69, 365-371.

Ebo, D.G., Hagendorens, M.M., Bridts, C.H., De Clerck, L.S. \& Stevens, W.J. (2004): Sensitization to crossreactive carbohydrate determinants and the ubiquitous protein profilin: mimickers of allergy. Clin. Exp. Allergy, 34(1), 137-144.

Holzweber, F., Svehla, E., Fellner, W., Dalik, T., Stubler, S., Hemmer, W. \& Altmann, F. (2013): Inhibition of IgE binding to cross-reactive carbohydrate determinants enhances diagnostic selectivity. Allergy, 68, 1269-1277.

LASNE, F. (2001): Double-blotting: a solution to the problem of non-specific binding of secondary antibodies in immunoblotting procedures. J. Immunol. Methods, 253(1), 125-131. 
López-Matas, M.A., Larramendi, C.H., Huertas, A.J., Ferrer, A., Moya, I.R., Pagán, J.A., Navarro, L.A., GarcíaAbujetA, J.L. \& CARNés, J. (2014): Tomato nsLTP as an "in vivo" diagnostic tool: Sensitization in a Mediterranean population. J. Invest. Allerg. Clin., 25(3), 196-204.

Mari, A., Ooievaar-De Heer, P., Scala, E., Giani, M., Pirrotta, L. \& Zuidmeer, L. (2008): Evaluation by doubleblind placebo-controlled oral challenge of the clinical relevance of $\mathrm{IgE}$ antibodies against plant glycans. Allergy, 63, 891-896.

Martino, M.D., Novembre, E., Cozza, G., Marco, A.D., Bonazza, P. \& Vierucci, A. (1988): Sensitivity to tomato and peanut allergens in children monosensitized to grass pollen. Allergy, 43, 206-213.

Romano, A., Scala, E., Rumi, G., Gaeta, F., Caruso, C., Alonzi, C., Maggioletti, M., Ferrara, R., Palazzo, P., Palmieri, V., Zeppilli, P. \& Mari, A. (2012): Lipid transfer proteins: the most frequent sensitizer in Italian subjects with food-dependent exercise-induced anaphylaxis. Clin. Exp. Allergy, 42, 1643-1653.

Westphal, S., Kolarich, D., Foetisch, K., Lauer, I., Altmann, F., Conti, A., Crespo, J.F., Rodríguez, J., Enrique, E., Vieths, S. \& Scheurer, S. (2003): Molecular characterization and allergenic activity of Lyc e 2 ( $\beta$-fructofuranosidase), a glycosylated allergen of tomato. Eur. J. Biochem., 270, 1327-1337.

Zacharius, R.M., Zell, T.E., Morrison, J.H. \& Woodlock, J.J. (1969): Glycoprotein staining following electrophoresis on acrylamide gels. Anal. Biochem., 30(1), 148-152. 